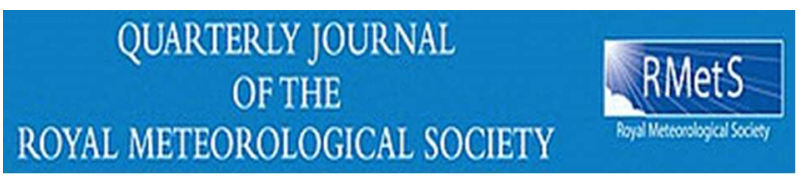

\title{
The influence of diabatic heating in the South Pacific Convergence Zone on Rossby wave propagation and the mean flow
}

\begin{tabular}{|r|l|}
\hline Journal: & QJRMS \\
\hline Manuscript ID: & QJ-15-0136.R2 \\
\hline Wiley - Manuscript type: & Research Article \\
\hline Date Submitted by the Author: & O6-Sep-2015 \\
\hline Complete List of Authors: & $\begin{array}{l}\text { van der Wiel, Karin; University of East Anglia, Centre for Ocean and } \\
\text { Atmospheric Sciences } \\
\text { Matthews, Adrian; University of East Anglia, School of Environmental } \\
\text { Sciences } \\
\text { Joshi, Manoj; University of East Anglia, Centre for Ocean and Atmospheric } \\
\text { Sciences } \\
\text { Stevens, David; University of East Anglia, }\end{array}$ \\
\hline Keywords: & $\begin{array}{l}\text { SPCZ, diabatic heating, tropical-extratropical interactions, Rossby waves, } \\
\text { IGCM4 }\end{array}$ \\
\hline
\end{tabular}




\title{
The influence of diabatic heating in the South Pacific Convergence Zone on Rossby wave propagation and the mean flow
}

\author{
Karin van der Wiel ${ }^{\mathrm{a}, \mathrm{b} *}$, Adrian J. Matthews ${ }^{\mathrm{a}, \mathrm{b}, \mathrm{c}}$, Manoj M. Joshi ${ }^{\mathrm{a}, \mathrm{b}, \mathrm{d}}$, David P. Stevens ${ }^{\mathrm{a}, \mathrm{c}}$ \\ ${ }^{a}$ Centre for Ocean and Atmospheric Sciences, University of East Anglia, Norwich UK \\ ${ }^{\mathrm{b}}$ School of Environmental Sciences, University of East Anglia, Norwich UK \\ ${ }^{\mathrm{c}}$ School of Mathematics, University of East Anglia, Norwich UK \\ ${ }^{\mathrm{d}}$ Climatic Research Unit, University of East Anglia, Norwich, UK \\ *Correspondence to: K. van der Wiel, School of Environmental Sciences, University of East Anglia, Norwich Research Park, \\ Norwich, NR4 7TJ, UK. E-mail: k.van-der-wiel@uea.ac.uk
}

The South Pacific Convergence Zone (SPCZ) is a northwest-southeast oriented precipitation band over the South Pacific Ocean. Latent heat release from condensation leads to substantial diabatic heating, which has potentially large impacts on local and global climate. The influence of this diabatic heating within the SPCZ is investigated using the Intermediate General Circulation Model (IGCM4).

Precipitation in the SPCZ has been shown to be triggered by transient Rossby waves that originate in the Australian subtropical jet and are refracted towards the equatorial eastern Pacific. A Rossby wave triggers a SPCZ 'convective event', with associated diabatic heat release and vortex stretching. Consequently, the Rossby wave is dissipated in the SPCZ region. These features are simulated well in a control integration of IGCM4.

In an experiment, convective heating is prescribed to its 'climatological' value in the SPCZ region during the Rossby wave 'events' and dynamic forcing from Rossby waves is decoupled from the usual thermodynamic response. In this experiment Rossby waves over the SPCZ region are not dissipated, confirming the vortex stretching mechanism from previous studies. Furthermore, the change in Rossby wave propagation has an impact on momentum transport. Overall, the effect of the Rossby wave-induced convection in the SPCZ is to decrease the strength of the Pacific subtropical jet and the equatorial eastern Pacific upper-tropospheric westerlies, by about 2-6 $\mathrm{m} \mathrm{s}^{-1}$.

Following these changes to the basic state, two potential feedbacks in the SPCZ and larger Pacific climate system are suggested: increased SPCZ convection due to the enhancement of negative zonal stretching deformation in the SPCZ region and decreased equatorward refraction of Rossby waves into the westerly duct leading to less SPCZ 'events'. As the convective events in the SPCZ have a significant impact on Pacific mean climate, it is crucial that the SPCZ is represented correctly in climate models.

Key Words: SPCZ; diabatic heating; tropical-extratropical interaction; Rossby waves

Received... 


\section{Introduction} over the southwestern Pacific Ocean (Figure 1a). It stretches diagonally, northwest-southeast, from New Guinea to about $30^{\circ} \mathrm{S}, 120^{\circ} \mathrm{W}$ in the central Pacific Ocean (Vincent 1994). 7 Its diagonal orientation is fundamentally different from the zonally oriented Intertropical Convergence Zone (ITCZ) in the northern hemisphere. The SPCZ provides vital precipitation to many Pacific island states. Past changes in its strength or position due to intraseasonal (e.g. the Madden-Julian Oscillation, MJO), interannual (e.g. El Niño-Southern Oscillation, ENSO) or interdecadal (e.g. the Interdecadal Pacific Oscillation, IPO) variability have had significant influences on the region (Griffiths et al. 2003; Kumar et al. 2006; Vincent et al. 2011; Cai et al. 2012; Haffke \& Magnusdottir 2013; Murphy et al. 2014).

The large-scale SPCZ precipitation pattern was first observed when satellite images became available (Hubert 1961; Streten 1973). Since then, many studies have shown that tropicalextratropical interactions by means of transient Rossby waves are related to SPCZ precipitation (e.g. Trenberth 1976; Kiladis \& Weickmann 1992, 1997; Matthews et al. 1996; Widlansky et al. 2011; Matthews 2012; Van der Wiel et al. 2015a). Atmospheric processes on intraseasonal and interannual time scales (e.g. MJO, ENSO) set an atmospheric mean state on which synoptic Rossby waves propagate (Meehl et al. 2001). Rossby wave propagation is limited to areas where the mean zonal wind field $(\bar{u})$ is westerly relative to the phase speed of the wave $(c)$, i.e. $\bar{u}-c>0$. At the boundary $\bar{u}-c=0$ Rossby waves are evanescent; in areas of mean relative easterly winds $(\bar{u}-c<0)$ there will be no influence by Rossby waves from outside this region. Zonal and meridional asymmetries of the atmospheric mean state direct propagating Rossby waves, e.g. jet streams can act as a wave guide, and the upper-tropospheric westerly winds over the equatorial east Pacific and Atlantic (the 'westerly ducts') play an important role in steering waves exiting the jet (Hoskins \& Ambrizzi 1993; Ambrizzi et al. 1995). Transient Rossby waves are a crucial part of the tropical momentum balance (Kiladis 1998).

Besides tropical-extratropical interactions, other (local) processes have also been suggested to impact the SPCZ. The direct atmospheric impact of land-sea contrasts and orography is minimal (Kiladis et al. 1989; Widlansky et al. 2011; Van der Wiel et al. 2015b). However, the blocking effect of the Andes mountain range enhances subsidence and cools Sea Surface Temperatures (SSTs) locally over the eastern Pacific. Both processes result in an enhancement of the east Pacific dry-zone, which influences the eastern margin of the SPCZ (Takahashi \& Battisti 2007a,b; Lintner \& Neelin 2008; Niznik \& Lintner 2013). Moisture transport and convergence in the lower troposphere are important factors in establishing the SPCZ diagonal orientation (Van der Wiel et al. 2015b).

In Matthews (2012) and Van der Wiel et al. (2015a) observational-based data products are used to develop a framework to describe a mechanism that forces diagonal bands of convective precipitation in the SPCZ. Rossby waves from the Australian subtropical jet are refracted towards the westerly duct over the equatorial eastern Pacific. In this process, initial circular vorticity centres are elongated and develop a northwest-southeast, diagonal, orientation, caused by advection by the mean flow and Rossby refraction (Hoskins et al. 1983; Van der Wiel et al. 2015a). Ahead of cyclonic vorticity centres poleward flow enhances ascent in a band parallel to the diagonally oriented cyclone. In the tropical conditionally unstable atmosphere this triggers deep convection. Latent heat release in the convection enhances the ascending motions. The upper-tropospheric divergence associated with the convection and ascent is a source of anticyclonic vorticity through vortex stretching. The propagating cyclonic vorticity centres encounter this anticyclonic tendency; consequently the cyclones are weakened and dissipated in situ.

In this framework, Rossby waves ultimately dissipate themselves by means of a negative feedback involving convection and diabatic heating due to latent heat release from condensation. This is consistent with the observation of Trenberth (1976) that the SPCZ area acts as a 'graveyard region for fronts moving from the southwest'. This is associated with the deceleration of Rossby waves over the SPCZ area due to negative zonal stretching deformation in the basic state $(\partial U / \partial x<0)$, as discussed by Widlansky et al. (2011). Here, we will test the validity of 
the proposed framework in an Atmospheric General Circulation Model (AGCM) of intermediate complexity. Furthermore, we will investigate the influence of diabatic heating from convective events in the SPCZ on the regional mean flow. Tropical convection and associated heating is a substantial source of energy, the dynamical responses to this forcing has been the topic of many studies. Theoretically, the Gill-Matsuno model explains the generation and development of an equatorial Kelvin and Rossby wave response to localised tropical heating (e.g. as observed in the MJO, Matsuno 1966; Gill 1980). However, the dynamical response to tropical heating is not limited to the tropics (e.g. Qin \& Robinson 1993; Jin \& Hoskins 1995; Matthews et al. 2004). The explicit influence of diabatic heating within the SPCZ has, to the authors knowledge, not been investigated before. Following the SPCZ mechanism in the framework of Matthews (2012) and Van der Wiel et al. (2015a), an AGCM experiment has been designed in which the thermodynamical response to dynamical Rossby wave forcing is removed in the SPCZ region. Potential changes to the Rossby wave and the south Pacific mean flow will be investigated. In Section 2 the AGCM used in the experiments is described. The perturbation experiment is explained in more detail in Section 3. The results are described in Section 4 and finally the findings are summarised in Section 5.

\section{Model description}

The Intermediate General Circulation Model version 4 (IGCM4, Joshi et al. 2015) has been used in this study. It is an AGCM of intermediate complexity, i.e. within the hierarchy of climate models it has simpler parametrisation schemes than state-of-the-art AGCMs (e.g. the AGCMs in the Coupled Model Intercomparison Project phase 5, CMIP5). This makes the model well-suited for idealised experiments to increase process-level understanding.

IGCM4 is used here in its T42L20 configuration, i.e. 128 cells in longitude and 64 cells in latitute in the horizontal grid and 20 layers in the vertical. A monthly mean climatological seasonal cycle of SST, based on NOAA's Optimum Interpolation V2 dataset, is prescribed (Reynolds et al. 2002, mean over 19822009). Land surface temperatures are computed self-consistently from surface fluxes (Forster et al. 2000). IGCM4 runs the
Morcrette radiation scheme (Zhong \& Haigh 1995) once for each model day. The parametrization for convective adjustment is based on the scheme of Betts (1986), it is slightly modified as described in Joshi et al. (2015). Cloud cover is computed to match observed profiles of convective clouds (Slingo 1987); there is no aerosol forcing. A more detailed description of the physical parametrizations in IGCM4 is given in Joshi et al. (2015).

The November to April time mean precipitation for observations and in the IGCM4 control integration are in good agreement (Figure 1). Data from the CPC merged analysis precipitation (CMAP) project have been used here as observations (Xie \& Arkin 1997, mean over 1982-2009). Globally the quality of simulated precipitation in IGCM4 is within the range of CMIP5 atmosphere-only ('AMIP') experiments (Joshi et al. 2015). For the current study it is more relevent that SPCZ location and orientation are simulated well in IGCM4, though the simulated precipitation rate within the SPCZ is slightly lower than observed (Figure 1).

\section{Experimental design}

The aim of the current paper is to investigate the influence of diabatic heating from convective activity in the SPCZ on other aspects of the Pacific climate. With this in mind we have designed a perturbation experiment in which SPCZ convective events are removed. The experiment is based on the transient wave - convection framework (Matthews 2012; Van der Wiel et al. 2015a). Figure 2 shows a flow diagram that depicts the consecutive steps in the experiment, each described in more detail below.

First, an IGCM4 control integration was conducted. This integration was 17 years long, from which the first year was removed as spin-up. The remaining 16 years of data contained 15 full November to April seasons (step 1 in Figure 2). Within these seasons, 140 SPCZ 'convective events' were selected, based on Empirical Orthogonal Functions (EOFs). EOF spatial patterns of variability were computed from daily anomalies of Outgoing Longwave Radiation (OLR) in a box over the SPCZ region $\left(180^{\circ}\right.$ $120^{\circ} \mathrm{W}, 5^{\circ}-30^{\circ} \mathrm{S}$, rectangle in Figure 3). In the tropics, OLR can 
be used as a proxy for precipitation; lower values are associated with colder temperatures, higher cloud tops and enhanced deep convection, higher values with warmer temperatures, lower cloud tops and reduced deep convection. The Principle Component (PC) time series associated with EOF 1 is then used for the selection of the convective events. If the value of the PC was above 1 standard deviation and was a local maximum relative to 5 days before and 5 days after that day, it was selected as a convective event (step 2 in Figure 2).

In the control integration, the computed temperature tendencies in the deep convection routine were saved at every timestep. These temperature tendency data were used to compute a threedimensional monthly varying climatology (step 3 in Figure 2), to be used in the perturbation experiment.

\subsection{Perturbation experiment}

The perturbation experiment aims to prevent dynamical forcing from Rossby waves from generating the observed anomalous diabatic heating response in the SPCZ region (Matthews 2012; Van der Wiel et al. 2015a). The experiment is based on 140 restart integrations started 4 days before each of the 140 selected convective events in step 2. At this time (event -4 days) the dynamical transient Rossby wave forcing is present, but the convective response in the SPCZ region has not commenced. From this atmospheric state a modified IGCM4 was integrated for 14 days (i.e. up to 10 days after the event). In the modified model all grid cells overlying ocean in the SPCZ region $\left(140^{\circ} \mathrm{E}-120^{\circ} \mathrm{W}, 0^{\circ}-40^{\circ} \mathrm{S}\right.$, rectangle in Figure $\left.1 \mathrm{~b}\right)$ have the deep convective temperature tendency prescribed from the precalculated climatological tendency in step 3 rather than computed self-consistently within the model code; i.e. instead of allowing the deep convection scheme to compute temperature tendencies, the climatological values were used. Moisture tendendies and precipitation were computed as normal to avoid an unrealistic build up or removal of moisture. Outside the SPCZ region the model code was integrated as normal. The perturbation experiment is the composite mean of all restart integrations (step 4 in Figure 2).
In the next section results from the different steps are discussed

separately. Steps 1 and 2 will be discussed in Subsection 4.1, 194 step 3 in 4.2 and finally step 4 in 4.3 and 4.4 .

\section{Experimental results}

\subsection{Transient wave - convection feedback in control integration}

The first mode of variability from EOF analysis $(7.8 \%$ of total variance) shows enhanced convection (negative OLR anomalies) 199 shifted to the southwest, however it remains parallel to the 200 SPCZ mean precipitation axis (Figure 3a). To the northeast 201 a parallel band of reduced convection is found. The second 202 mode of variability (7.3\%, not shown, well-separated from 203 EOF1 and further EOFs, North et al. 1982) shows enhanced 204 convection over the mean precipitation axis and reduced 205 convection to the southwest. These 'southwestward shifted' and 206 'enhanced' convection patterns are comparable to patterns found in observational data (e.g. Vincent et al. 2011; Matthews 2012;

Following the criteria presented in Section 3, 140 events of the 210 southwestward shifted mode have been selected from the EOF 211 1 PC time series (Figure 3b). Composite means were computed 212 by taking the mean of a field over all event days. Anomalies of 213 $200 \mathrm{hPa}$ vorticity and precipitation for these convective events are 214 shown in Figure 4. Four days before the event a Rossby wave 215 train is present south of Australia. As was found in observational- 216 based data, over the following days, the wave is refracted along 217 a curved path towards the equatorial east Pacific. During this 218 process the combined effect of advection by the mean wind, 219 shear on the equatorward edge of the jetstream and Rossby wave 220 refraction changes the shape of the vorticity centres (Van der 221 Wiel et al. 2015a); the centres develop a northwest-southeast 222 diagonal orientation, parallel to the SPCZ mean precipitation axis 223 (Figure $4 \mathrm{~b}$ ). This process is further supported by the meridional 224 stretching deformation of the basic state (Widlansky 2010). 225

Two days before the convective event the Rossby wave 226 initiates enhanced precipitation. Ahead of a cyclonic vorticity 227 anomaly, poleward wind ascends and in the tropical conditionally 228 unstable atmosphere this triggers deep convection. The vorticity 229 centre propagates northeastward with the Rossby wave, the 230 
associated precipitation signal remains ahead of the cyclone at all times. At the day of the convective event, by design of the composite method, the precipitation anomaly reaches a maximum $\left(\sim 10 \mathrm{~mm} \mathrm{~d}^{-1}\right)$ and the pattern resembles the southwestward shifted pattern of EOF 1; there is a diagonal band of enhanced precipitation to the southwest of the SPCZ mean precipitation axis and reduced precipitation to the northeast. Two days after the convective event the precipitation anomalies have mostly disappeared (Figure 4d).

The diabatic heat release from the precipitation anomalies is substantial and enhances ascending motions and uppertropospheric divergence. Through vortex stretching this acts as a negative feedback, $\partial \zeta / \partial t=-f D$, where $\zeta$ is relative vorticity, $t$ is time, $f$ is the Coriolis parameter and $D$ is divergence, and results in an anticyclonic tendency: the propagating cyclone in the Rossby wave is dissipated. Consequently, Rossby wave propagation is disturbed downstream of the SPCZ region. The effect is clear in the evolution of the vorticity centres in the Rossby wave in Figure 4, at the moment precipitation anomalies are triggered propagation of the upstream cyclonic vorticity centre slows down and weakens. The Rossby wave favours a more southern propagation path, back towards the wave guide in the jet, where both precipitation anomalies and the negative feedback effect are weaker. Two days after the convective event the wave is mostly dissipated.

The sequence of events forcing diagonally oriented bands of precipitation in the IGCM4 control integration is similar to the sequence found using similar methods and observational-based data products (Matthews 2012; Van der Wiel et al. 2015a). The realistic representation of this process makes IGCM4 a suitable AGCM for the perturbation experiment.

\subsection{Diabatic heating from deep convection}

The simulated November to April time mean mid-tropospheric climatological heating due to deep convection is shown in Figure 5a. Higher values of diabatic heating are found at locations with frequent convective precipitation, lower values in areas of less precipitation (Figures 1b, 5a). The SPCZ, ITCZ, South Atlantic Convergence Zone (SACZ) and South Indian Convergence Zone can all be identified as areas of enhanced diabatic heating from deep convection. The south Pacific dry zone

has very weak diabatic heating from deep convection.

Figures 5b,c show vertical sections of the same quantity. The 272 black areas on the cross-section show the grid cells where the 273 IGCM4 deep convection scheme has not once been initiated in 274 the 15 seasons included in the control integration (effectively 275 the stratosphere). For these cells a climatological heating of 276 $0 \mathrm{~K}$ timestep $^{-1}$ is assumed in the experimental integration. Along 277 $155^{\circ} \mathrm{E}$ (Figure $5 \mathrm{~b}$ ) the region of most intense heating lies over the equator, where the SPCZ and ITCZ merge. In this region, there is a slight negative temperature tendency at the surface due to 280 evaporative cooling, in the mid-troposphere there is substantial 28 diabatic heating and near the model top $(\sigma=0.05)$ there is a 282 negative temperature tendency due to radiative cooling. Further 283 east at $149^{\circ} \mathrm{W}$ (Figure 5c) the heating profiles related to the SPCZ 284 and ITCZ are weaker and separated and found at about $20^{\circ} \mathrm{S}$ and 285 $8^{\circ} \mathrm{N}$ respectively.

These climatological temperature tendency data are used

in the perturbation experiment. Instantaneous, self-consistent 288 temperature tendencies are used in the control integration (left 289 column of Figure 6). This heating pattern is more irregular than 290 in the climatology, changes fast in time and has larger extremes. 291 Following the earlier discussion, it can be seen that ahead 292 of upper-tropospheric cyclonic vorticity anomalies convective 293 heating is strongest. As the cyclone propagates northeastward this 294 region of enhanced heating also moves northeastward, similar 295 to the progression of precipitation anomalies (Figure 4). Ahead 296 of anticyclonic vorticity anomalies convective heating is weaker. 297 In the perturbation experiment, as discussed in Section 3, in 298 the SPCZ region this instantaneous, self-consistent temperature 299 tendency is replaced by the relevant climatological value from the 300 seasonal cycle appropriate for each of the 140 restart integrations. 301 The composite mean temperature tendencies as used in the 302 experimental model integration are shown in the right column of 303 Figure 6. Outside the rectangular SPCZ region there has been 304 no change from the control integration (small differences due 305 to separate integrations in control and experiment), inside the 306 rectangular region instantaneous values have been replaced by 307 climatological values (compare horizontal rows in Figure 6). 
As described in Section 3, the restart integrations are initiated from the control integration at 4 days before the 140 selected convective events. At this moment a Rossby wave train is present south of Australia (Figure 7a). Two days into the perturbation experiment, the Rossby wave has propagated northeastward into the SPCZ region (Figure 7b). Ahead of the cyclonic anomaly is an anomalous poleward flow that leads to ascent along the sloping mean isentropes. There is a small anomalous precipitation signal associated with this ascent $\left(\sim 2 \mathrm{~mm} \mathrm{~d}^{-1}\right)$. However, the associated anomalous diabatic heat release is removed in the experiment so no additional ascending motions are forced. This results in a much weaker precipitation rate in the perturbation experiment than in the control integration at this point $\left(\sim 8 \mathrm{~mm} \mathrm{~d}^{-1}\right.$, Figure $\left.4 \mathrm{~b}\right)$.

In the following days this process continues. Vorticity centres in the wave propagate northeastward. Ahead of the cyclonic vorticity anomaly and along the SPCZ mean precipitation axis there is some anomalous precipitation. However, the precipitation rates are constant around $\sim 2 \mathrm{~mm} \mathrm{~d}^{-1}$; there is no distinct peak in precipitation rates at the convective event as was found in the control integration.

In the sequence of events that ultimately triggers diagonal bands of convective precipitation over the SPCZ region in the control integration, the negative feedback from vortex stretching starts influencing Rossby wave propagation two days before the convective event. When the convective heating response is taken out of the sequence, diabatic heating, ascending motions and upper-tropospheric divergence are all significantly weaker than in the control integration. The maximum composite-mean upper-tropospheric divergence in the perturbation experiment is $4 \times 10^{-6} \mathrm{~s}^{-1}$, only $30 \%$ of the divergence in the control integration $\left(13 \times 10^{-6} \mathrm{~s}^{-1}\right)$. The negative feedback, $\partial \zeta / \partial t=$ $-f D$, is therefore much weaker and has a smaller effect on the transient Rossby wave.

The northeastward propagation of the Rossby wave is undisturbed in the perturbation experiment. The vorticity centres are reformed due to shear and Rossby refraction as in the control integration, though the effects are more obvious in the experiment.
Vorticity centres become elongated and rotate from a diagonal 348 orientation (northwest-southeast) to a zonal orientation at the 349 equator (Figure 7c). The southward tendency of the wave pattern 350 in the control integration is not found in the experiment, instead 351 Rossby wave propagation continues across the equator.

The propagation speed of the Rossby wave can be estimated 353 from a Hovmöller diagram (Figure 8). The vorticity centres move 354 eastward steadily at the phase speed; wave energy moves through 355 the region at the faster group speed. In the perturbation experiment 356 the phase speed is about $580 \mathrm{~km} \mathrm{~d}^{-1} \approx 6.7 \mathrm{~m} \mathrm{~s}^{-1}$, the group 357 speed approximately $2000 \mathrm{~km} \mathrm{~d}^{-1} \approx 23 \mathrm{~m} \mathrm{~s}^{-1}$ (grey dotted 358 lines in Figure 8). These values are comparable in the control 359 integration, however wave propagation downstream of the SPCZ 360 mean precipitation axis is disturbed. The cyclone at $180^{\circ}$ weakens 361 when precipitation is triggered 2 days before the convective event, 362 in the perturbation experiment the cyclone is present for longer 363 and propagates further eastward. The same effect appears for the 364 anticyclone at $160^{\circ} \mathrm{W}$. In both model integrations propagation 365 slows down close to the equator at about $130^{\circ} \mathrm{W}$. Not visible 366 in the Hovmöller diagram is the different shape of the Rossby 367 waves after the convective events in the control integration and perturbation experiment (Figures $4 d$ and $7 d$ ).

As precipitation rates decrease significantly in the perturbation experiment, there is a slight build up of moisture in the 371 experimental region of up to $2 \mathrm{~g} \mathrm{~kg}^{-1}$ in specific humidity at 372 $850 \mathrm{hPa}$. This moisture is advected by horizontal winds out of the 373 experimental region. This results in enhanced precipitation over 374 New Guinea and in a zonal line just north of the experimental 375 region (Figures 7c,d), as the model computes convective 376 temperature tendencies self-consistently there. The increased 377 moisture content does increase modelled low level clouds and 378 through a radiative feedback lowers surface temperatures in the SPCZ region slightly. The impact of this side effect on Rossby wave propagation in the experimental region is small.

\subsection{Impact of diabatic heating on the mean flow}

Six days after the convective event the Rossby wave has 383 disappeared in both the control integration and in the perturbation 384 experiment. In the control integration the upper troposphere has 385 returned to its 'normal' state (Figure 9a); anomalies of zonal wind 
speed are very small (less than $2 \mathrm{~m} \mathrm{~s}^{-1}$ ). There is no coherent pattern to these anomalies over most of the Pacific Ocean, though there is a hint of a wave train over South America, from the southeast Pacific towards the equatorial Atlantic. A similar wave train has been linked to enhanced SACZ activity (e.g. Liebmann et al. 1999; Robertson \& Mechoso 2000; Van der Wiel et al. 2015a). By means of influence functions, Grimm \& Silva Dias (1995) found a link between convection in the SPCZ and in the SACZ. However, no significant lagged correlations were found between convective events in the SPCZ and subsequent convective events in the SACZ in the IGCM4 control integration.

The post-convective event upper tropospheric zonal wind anomalies in the perturbation experiment are much larger (Figure 9b). Along the Rossby wave propagation path and over the equatorial east Pacific there are strong positive (westerly) anomalies. To the north and south of the propagation path there are negative (easterly) anomalies. The anomaly pattern is approximately southwest-northeast, perpendicular to the prescribed heating pattern, which suggests it is not a direct effect in response to the prescribed heating but rather has a different, dynamical origin.

In the control integration and in the actual climate system, there are two processes that feedback from SPCZ activity onto the basic state wind. In general, tropical heating results in an off-equatorial anticyclone that accelerates the subtropical jets, through a Gilllike response (Gill 1980). Additionally, the diagonal, northwestsoutheast, orientation of the vorticity centres in the waves leads to a mean poleward transport of westerly momentum in these waves, as anomalies of the zonal and meridional wind are anticorrelated in the wave $\left(\overline{u^{\prime} v^{\prime}}<0\right.$, see also Kiladis 1998). These two processes determine, in part, the strength of the modelled climatological subtropical jet at $30^{\circ} \mathrm{S}$. The Gill-response and momentum transport by Rossby waves in the control run result in this climatological jet. The weak anomalies after the SPCZ events (Figure 9a) are just due to sampling variability.

In the perturbation experiment both processes are modified. Diabatic heating in the SPCZ region is limited, therefore the Gill anticyclone would be weaker and its acceleration of the subtropical jet would be decreased. However, this is not observed in the experiment (Figure 9b); the effect is off-set by the towards the SPCZ region and the westerly duct is enhanced, 428

leading to increased poleward transport of westerly momentum and positive anomalies of zonal wind in the subtropical jet. Rossby wave propagation from the SPCZ region back towards the subtropical jet is less favoured in this state, resulting in weaker poleward momentum transport and negative zonal wind anomalies at $40^{\circ} \mathrm{S}, 120^{\circ} \mathrm{W}$.

In the perturbation experiment the anomalous diabatic heating from SPCZ convection triggered by equatorward propagating Rossby waves has been switched off. Therefore, the climatological effect of this SPCZ convection on the basic state (contours in Figure 9c) will be the opposite of the effect in the perturbation experiment (Figure 9b). Dashed contours in Figure 9c show areas where the climatological westerly winds are decreased in strength or where climatological easterly winds are increased in strength; solid contours show areas of increased westerly/decreased easterly winds. Therefore, convective events in the SPCZ act to decrease the strength of the subtropical jet and the westerly winds along the wave propagation path. This results in an enhancement of the region of negative stretching deformation near the SPCZ. Following the mechanism discussed in Widlansky et al. (2011), this would increase the accumulation of wave energy there and increase convection along the SPCZ. The described feedback would be positive: convective events in the SPCZ increase the likelihood of further convective events.

Furthermore, the strength of the westerly duct over the equatorial eastern Pacific is decreased. The westerly duct is partially responsible for the initial equatorward propagation of the Rossby waves. In the IGCM4 control integration the zonal wind speed in the westerly duct is $\sim 20 \mathrm{~m} \mathrm{~s}^{-1}$ (colours in Figure 9c), a change of $\sim-4 \mathrm{~m} \mathrm{~s}^{-1}$ due to SPCZ convection is an important factor in determining its strength. This feedback would be negative: convective events in the SPCZ decrease the likelihood of wave refraction towards the SPCZ and the westerly duct, decreasing the chance of a next convective event.

The influence of convective events in the SPCZ on local 464 Rossby wave propagation and the Pacific mean flow has been 
tested by means of an AGCM experiment. In observational data and in the control integration, Rossby waves trigger deep convection and precipitation in the SPCZ. In a perturbation experiment the dynamical Rossby wave forcing is decoupled from a potential thermodynamical response: instantaneous diabatic heating during SPCZ convective events is removed and replaced by a climatological value. Experimental results show continued Rossby wave propagation from the subtropical jet towards the eastern equatorial Pacific and across the equator. In the control integration and in observations these Rossby waves are dissipated in the SPCZ region due to diabatic heat release in the convection and a negative feedback due to vortex stretching. The continued Rossby propagation in the experiment provides additional evidence for the feedback mechanism in the transient wave-convection framework proposed by Matthews (2012) and Van der Wiel et al. (2015a).

Besides influencing transient Rossby waves locally, the experiment shows convective events in the SPCZ region have a significant impact on the south Pacific upper-tropospheric zonal wind climate. As discussed, in the control integration and in observations, convective events in the SPCZ hinder Rossby wave propagation in the region. Consequently the poleward transport of westerly momentum is decreased, as transient Rossby waves are an important factor in the tropical momentum balance (Kiladis 1998). Convective events in the SPCZ act to weaken both the subtropical jet and the equatorial westerly duct. The first of these effects enhances the region of negative zonal stretching deformation potentially resulting in enhanced convection along the SPCZ (Widlansky et al. 2011). The second reduces the equatorward refraction of Rossby waves that trigger SPCZ convective events (Van der Wiel et al. 2015a). To determine the strength of these feedbacks requires further modelling experiments.

These results can be interpreted within the general framework of Meehl et al. (2001), where atmospheric processes on longer time scales and larger spatial scales set a mean atmospheric state on which synoptic waves propagate (the Rossby waves in the SPCZ in this example). In the general framework, processes on synoptic scales then influence atmospheric processes on synoptic time scales, but also on longer time and larger spatial scales.

Here, this corresponds to the effect convective activity has on the 506 atmospheric basic state through changed momentum transport. $\quad 507$ SST biases in coupled models in the Coupled Model 508 Intercomparison Project phase 5 (CMIP5) force a too zonal 509 tropical part of the SPCZ, which then gives a more discontinuous 510 simulated SPCZ than is observed (Brown et al. 2011, 2013; Niznik 511 et al. 2015). Such biases influence future rainfall projections of 512 the SPCZ (Widlansky et al. 2013). Based on the results presented 513 here, biases in the represented SPCZ lead to further biases in the 514 representation of convective heating, Rossby wave propagation, 515 momentum transport and the mean upper-tropospheric wind 516 climate. Projections of changes in atmospheric processes in a 517 future warmer climate are often based on these CMIP5 models, 518 it is therefore of importance to improve the representation of the 519 SPCZ in such models.

The CMAP data were provided by the NOAA/OAR/ESRL 522 PSD, Boulder, Colorado, USA, from their web site at 523 http://www.cdc.noaa.gov/. The research presented in this article 524 was carried out on the High Performance Computing Cluster 525 supported by the Research Computing Service at the University of 526 East Anglia. The authors would like to thank George Kiladis and 527 three anonymous reviewers for comments that helped to improve 528 the manuscript.

\section{References}

Ambrizzi, T, Hoskins, B J, \& Hsu, H-H. 1995. Rossby wave propagation and 531 teleconnection patterns in the austral winter. Journal of the Atmospheric Sciences, 52, $3661-3672$.

Betts, A K. 1986. A new convective adjustment scheme. Part I: Observational and theoretical basis. Quarterly Journal of the Royal Meteorological Society, 112, $677-691$.

Brown, J R, Power, S B, Delage, F P, Colman, R A, Moise, A F, \& Murphy, 534 535 B F. 2011. Evaluation of the South Pacific Convergence Zone in IPCC AR4 538 climate model simulations of the twentieth century. Journal of Climate, 24, 539 $1565-1582$.

Brown, J R, Moise, A F, \& Colman, R A. 2013. The South Pacific Convergence 541 Zone in CMIP5 simulations of historical and future climate. Climate 542 Dynamics, 41, 2179 - 2197. 


\section{Page 9 of 17 Quarterly Journal of the Royal Meteorological Society}

\& Widlansky, M J. 2012. More extreme swings of the South Pacific Convergence Zone due to greenhouse warming. Nature, 488, 365 - 370 .

Forster, P M de F, Blackburn, M, Glover, R, \& Shine, K P. 2000. An examination of climate sensitivity for idealised climate change experiments in an intermediate general circulation model. Climate Dynamics, 16, 833 849.

Gill, A E. 1980. Some simple solutions for heat-induced tropical circulation. Quarterly Journal of the Royal Meteorological Society, 106, 447 - 462.

Griffiths, G M, Salinger, M H, \& Leleu, I. 2003. Trends in extreme daily rainfall across the South Pacific and relationship to the South Pacific Convergence Zone. International Journal of Climatology, 23, 847 - 869.

Grimm, A M, \& Silva Dias, P L. 1995. Analysis of tropical-extratropical interactions with influence functinos of a barotropic model. Journal of the Atmospheric Sciences, 52, 3538 - 3555.

Haffke, C, \& Magnusdottir, G. 2013. The South Pacific Convergence Zone in three decades of satellite images. Journal of Geophysical Research, 118, 1 $-11$.

Hoskins, B J, \& Ambrizzi, T. 1993. Rossby wave propagation on a realistic longitudinally varying flow. Journal of Atmospheric Sciences, 50, 797 812 .

Hoskins, B J, James, I N, \& White, G H. 1983. The shape, propagation and mean-flow interaction of large-scale weather systems. Journal of the Atmospheric Sciences, 40, 1595 - 1612.

Hubert, L F. 1961. A subtropical convergence line of the South Pacific: a case study using meteorological satellite data. Journal of Geophysical Research, 66, $1661-1671$.

Jin, F, \& Hoskins, B J. 1995. The direct response to tropical heating in a baroclinic atmosphere. Journal of the Atmospheric Sciences, 52, 307 - 319. Joshi, M M, Stringer, M, Van der Wiel, K, O’Callaghan, A, \& Fueglistaler, S. 2015. IGCM4: a fast, parallel and flexible intermediate climate model. Geoscientific Model Development, 8, 1157-1167.

Kiladis, G N. 1998. Observations of Rossby waves linked to convection over the eastern tropical Pacific. Journal of Atmospheric Sciences, 55, 321 339.

Kiladis, G N, \& Weickmann, K M. 1992. Extratropical forcing of tropical Pacific convection during northern winter. Monthly Weather Review, 120, $1924-1938$

Kiladis, G N, \& Weickmann, K M. 1997. Horizontal structure and seasonality of large-scale circulations associated with submonthly tropical convection. Monthly Weather Review, 125, 1997-2013.

Kiladis, G N, von Storch, H, \& van Loon, H. 1989. Origin of the South Pacific Convergence Zone. Journal of Climate, 2, 1185 - 1195

Kumar, V V, Deo, R C, \& Ramachandran, V. 2006. Total rain accumulation and rain-rate analysis for small tropical Pacific islands: a case study of Suva, Fiji. Atmospheric Science Letters, 7, 53 - 58.

Liebmann, B, Kiladis, G N, Marengo, J A, Ambrizzi, T, \& Glick, J D. 1999. Submonthly convective variability over South America and the South
Atlantic convergence zone. Journal of Climate, 12, 1877 - 1891.

Lintner, B R, \& Neelin, J D. 2008. Eastern margin variability of the South 594 Pacific Convergence Zone. Geophysical Research Letters, 35, L16701. 595

Matsuno, T. 1966. Quasi-Geostrophic motions in the equatorial area. Journal 596 of the Meteorological Society of Japan, 44, 25-42.

Matthews, A J. 2012. A multiscale framework for the origin and variability 598 of the South Pacific Convergence Zone. Quarterly Journal of the Royal 599 Meteorological Society, 138, $1165-1178$.

Matthews, A J, Hoskins, B J, Slingo, J M, \& Blackburn, M. 1996.601 Development of convection along the SPCZ within a Madden-Julian 602 Oscillation. Quarterly Journal of the Royal Meteorological Society, 122, 603 $669-688$.

Matthews, A J, Hoskins, B J, \& Masutani, M. 2004. The global response to 605 tropical heating in the Madden-Julian Oscillation during northern winter. Quarterly Journal of the Royal Meteorological Society, 130, 1991 - 2011.

Meehl, G A, Lukas, R, Kiladis, G N, Weickmann, K M, Matthews, A J, \& Wheeler, M. 2001. A conceptual framework for time and space scale interactions in the climate system. Climate Dynamics, 17, 753 - 775 .

Murphy, B F, Power, S B, \& McGree, S. 2014. The varied impacts of El NiñoSouthern Oscillation on Pacific island climates. Journal of Climate, 27, $4015-4036$.

Niznik, M J, \& Lintner, B R. 2013. Circulation, moisture and precipitation relationships along the South Pacific Convergence Zone in reanalyses and CMIP5 models. Journal of Climate, 26, 10174 - 10192.

Niznik, M J, Lintner, B R, Matthews, A J, \& Widlansky, M J. 2015. The role of tropical-extratropical interaction and synoptic variability in maintaining the South Pacific Convergence Zone in CMIP5 models. Journal of Climate. accepted for publication.

North, G R, Bell, T L, \& Cahalan, R F. 1982. Sampling errors in the estimation of empirical orthogonal functions. Monthly Weather Review, 110, $699-$ 706.

Qin, J, \& Robinson, W A. 1993. On the Rossby Wave Source and the steady linear response to tropical forcing. Journal of the Atmospheric Sciences, 625 50, $1819-1823$.

Reynolds, R W, Rayner, N A, Smith, T M, Stokes, D C, \& Wang, W. 2002. An 627 improved in situ and satellite SST analysis for climate. Journal of Climate, 628 $15,1609-1625$.

Robertson, A W, \& Mechoso, C R. 2000. Interannual and interdecadal variability of the South Atlantic Convergence Zone. Monthly Weather Review, 128, 2947 - 2957.

Salinger, M J, McGree, S, Beucher, F, Power, S B, \& Delage, F. 2014. A new index for variations in the position of the South Pacific convergence zone 1910/11-2011/2012. Climate Dynamics, 43, 881 - 892.

Slingo, J M. 1987. The development and verification of a cloud prediction 636 scheme for the ECMWF model. Quarterly Journal of the Royal 637 Meteorological Society, 113, 899 - 927. 
639 640

641

Streten, N A. 1973. Some characteristics of satellite-observed bands of persistent cloudiness over the Southern Hemisphere. Monthly Weather Review, 101, 486 - 495.

Takahashi, K, \& Battisti, D S. 2007a. Processes controlling the mean tropical Pacific precipitation pattern. Part I: The Andes and the Eastern Pacific ITCZ. Journal of Climate, 20, 3434 - 3451.

Takahashi, K, \& Battisti, D S. 2007b. Processes controlling the mean tropical Pacific precipitation pattern. Part II: the SPCZ and the southeast Pacific dry zone. Journal of Climate, 20, 5696 - 5706.

Trenberth, K E. 1976. Spatial and temporal variations of the Southern Oscillation. Quarterly Journal of the Royal Meteorological Society, 102, $639-653$

Van der Wiel, K, Matthews, A J, Stevens, D P, \& Joshi, M M. 2015a. A dynamical framework for the origin of the diagonal South Pacific and South Atlantic Convergence Zones. Quarterly Journal of the Royal Meteorological Society. published online, doi: 10.1002/qj.2508.

Van der Wiel, K, Matthews, A J, Joshi, M M, \& Stevens, D P. 2015b. Why the South Pacific Convergence Zone is diagonal. Climate Dynamics. published online, doi: 10.1007/s00382-015-2668-0.

Vincent, D G. 1994. The South Pacific Convergence Zone (SPCZ): a review. Monthly Weather Review, 122, 1949 - 1970.

Vincent, E M, Lengaigne, M, Menkes, C E, Jourdain, N C, Marchesiello, P, \& Madec, G. 2011. Interannual variability of the South Pacific Convergence Zone and implications for tropical cyclone genesis. Climate Dynamics, 36, $1881-1896$.

Widlansky, M J. 2010. Climate dynamics of the South Pacific Convergence Zone and similarities with other subtropical convergence zones in the southern hemisphere. Ph.D. thesis, Georgia Institute of Technology.

Widlansky, M J, Webster, P J, \& Hoyos, C D. 2011. On the location and orientation of the South Pacific Convergence Zone. Climate Dynamics, 36, $561-578$.

Widlansky, M J, Timmermann, A, Stein, K, McGregor, S, Schneider, N, England, M H, Lengaigne, M, \& Cai, W. 2013. Changes in South Pacific rainfall bands in a warming climate. Nature Climate Change, 3, $417-423$.

Xie, P, \& Arkin, P A. 1997. Global precipitation: a 17-year monthly analysis based on gauge observations, satellite estimates, and numerical model outputs. Bulletin of the American Meteorological Society, 78, 2539 - 2558.

Zhong, W Y, \& Haigh, J D. 1995. Improved broad-band emissivity parameterization for water vapor cooling calculations. Journal of Atmospheric Sciences, 52, $124-138$. 

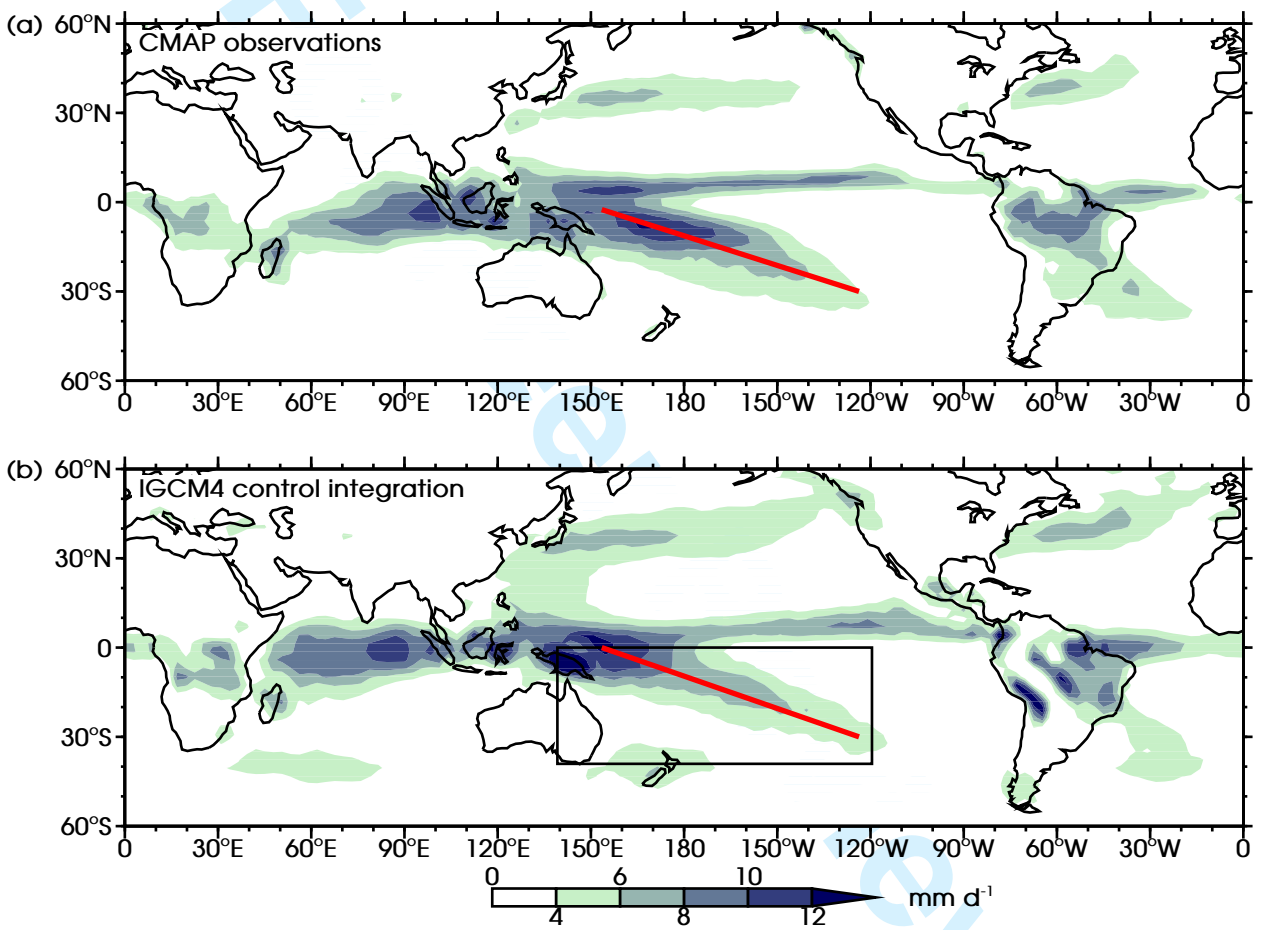

Figure 1. Time mean precipitation rate (November to April) in (a) CMAP and (b) the IGCM4 control integration (mm $\mathrm{d}^{-1}$ ). The thick diagonal red lines show the position of the mean SPCZ precipitation axis, the rectangle in (b) shows the region for the perturbation experiment. 


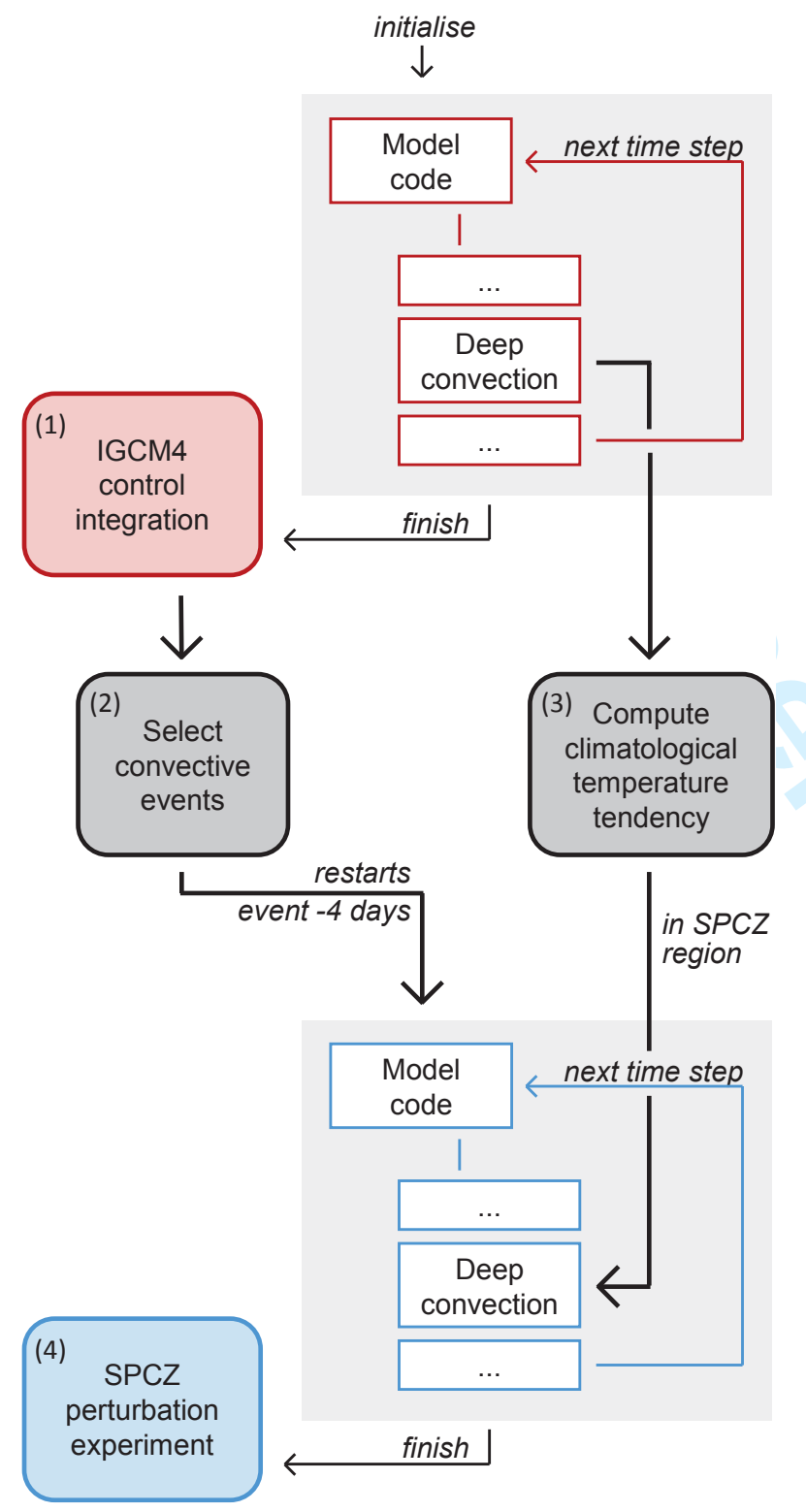

(a)

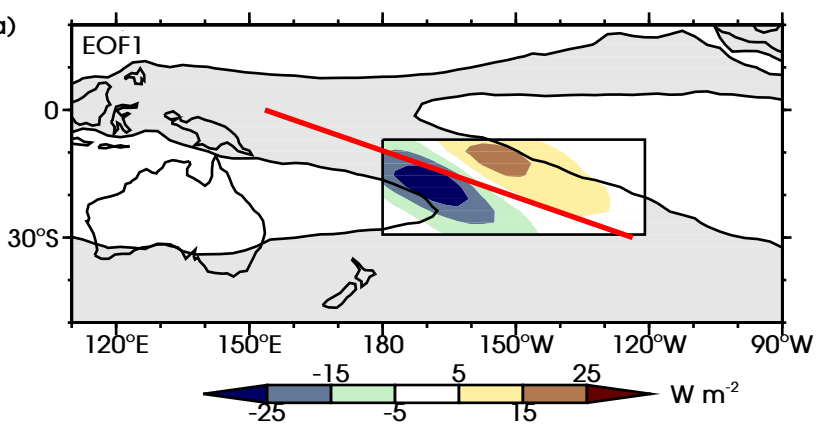

Figure 2. Flow diagram of experimental setup; detailed explanations of each step numbered (1) through (4) are provided in the main text (Section 3).

(b)

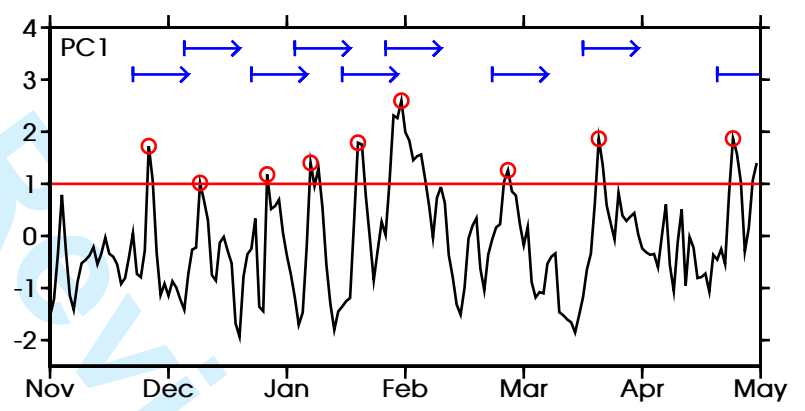

Figure 3. (a) EOF pattern 1 in shaded colours $\left(\mathrm{W} \mathrm{m}^{-2}\right)$ in the rectangular box, overlaid on the time mean OLR field (November to April, grey shading is $<250 \mathrm{~W} \mathrm{~m}^{-2}$ ). The thick diagonal red line shows the position of the SPCZ mean precipitation axis. (b) Sample time series of the PC associated with EOF 1 during November-April of model integration year 10. The red line and circles show the selection of SPCZ convective events, blue arrows show the duration of the associated restart integrations. 

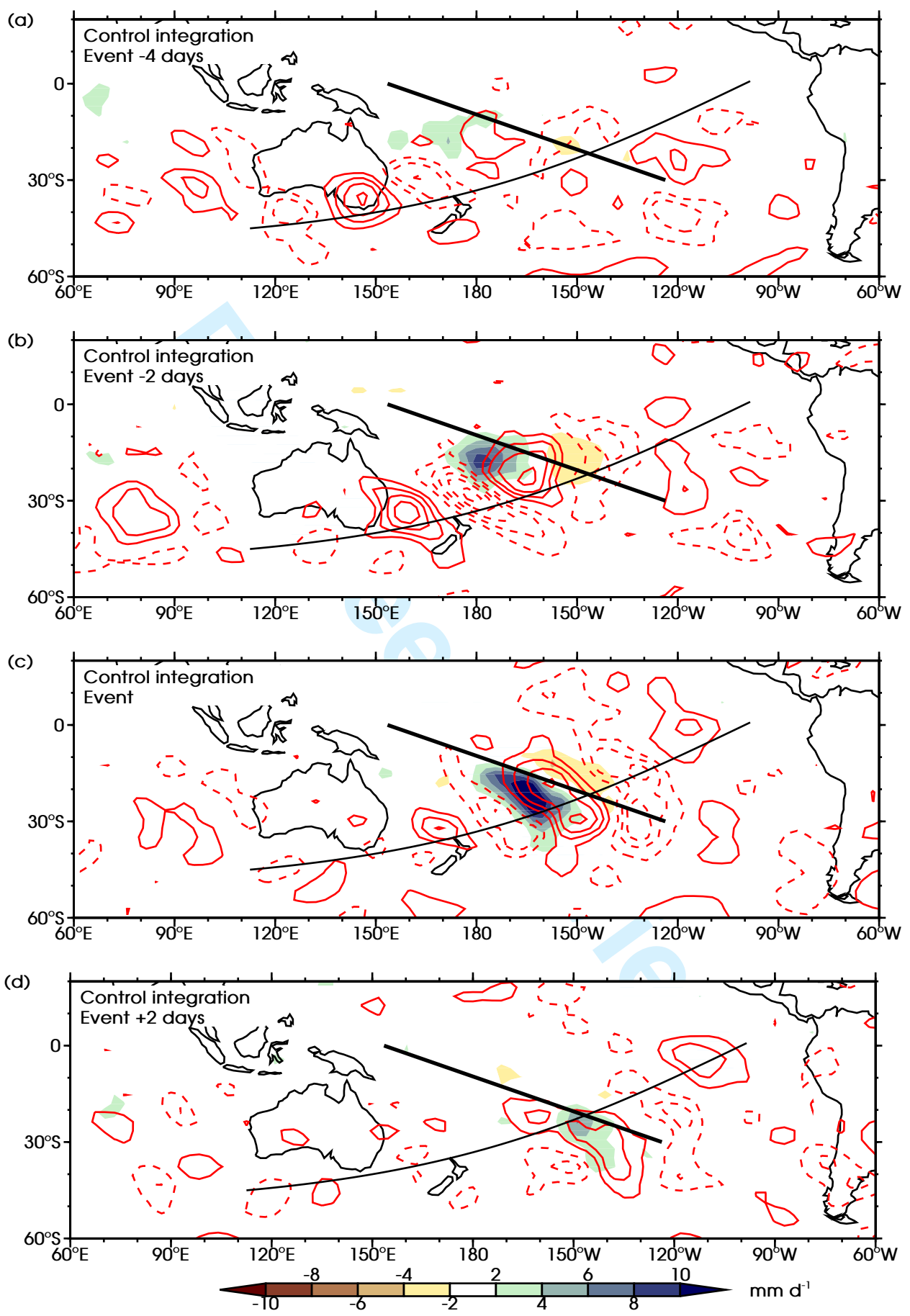

Figure 4. Composite mean anomalies over the 140 shifted SPCZ events of precipitation rate in shaded colours (mm $\mathrm{d}^{-1}$ ), and $200 \mathrm{hPa}$ vorticity in red contours $\left(4 \times 10^{-6} \mathrm{~s}^{-1}\right.$ contour interval, zero contour omitted, negative contours dashed) for the IGCM4 control integration. The thick diagonal line indicates the position of the SPCZ mean precipitation axis, the curved line an approximate wave propagation path. Time lags shown: (a) event -4 days, (b) event -2 days, (c) event, and (d) event +2 days. 

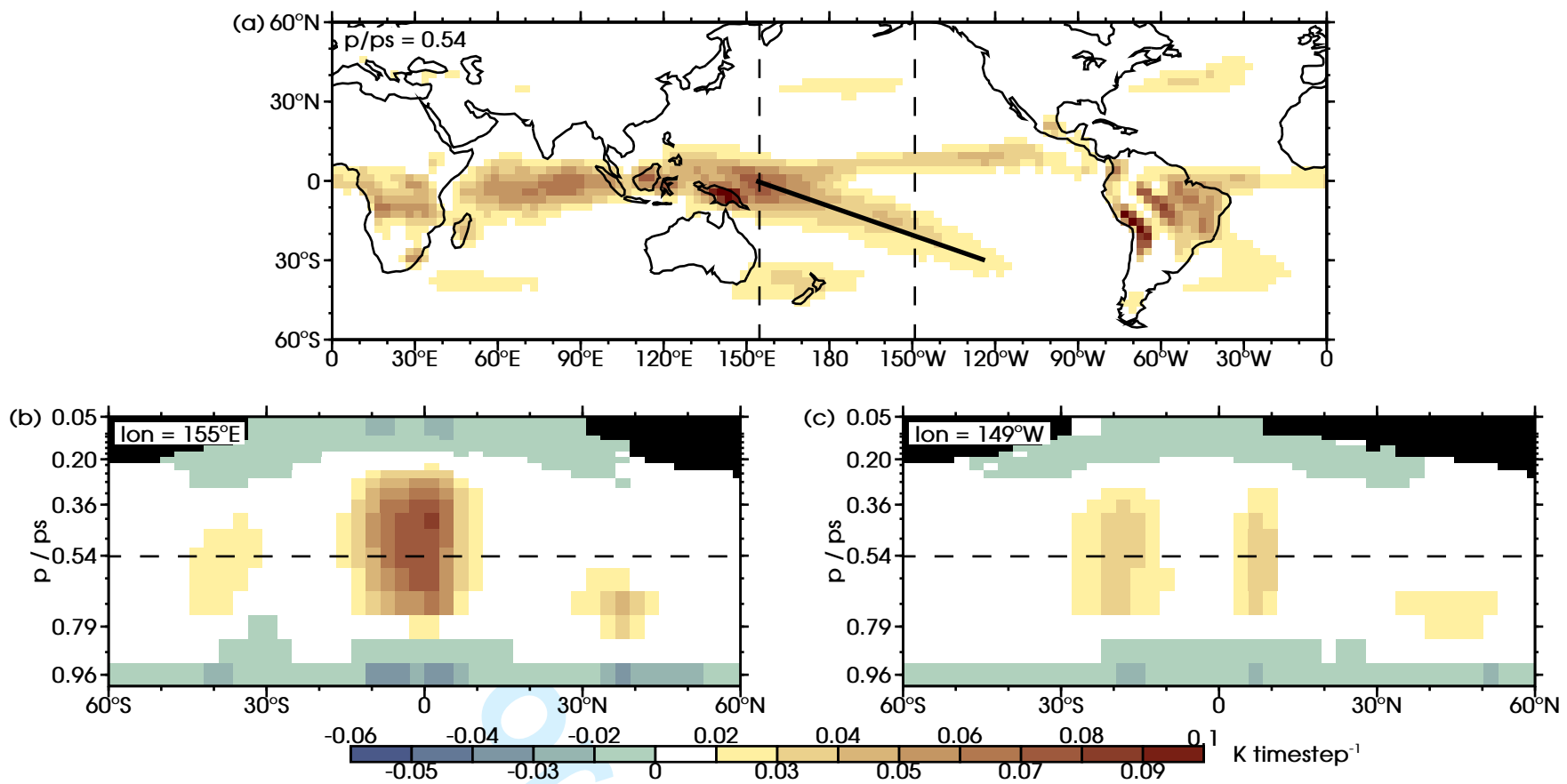

Figure 5. Time mean temperature tendency due to deep convection (November to April) in IGCM4 at (a) $p / p s=0.54$, and vertical sections at (b) $155^{\circ} \mathrm{E}$ and (c) $149^{\circ} \mathrm{W}$ in shaded colours (K timestep ${ }^{-1}$ ). Vertical levels are pressure $(p)$ / surface pressure $(p s)$ or sigma coordinates. Dashed lines in (a) show the locations of the vertical sections in (b,c), dashed lines in (b,c) show the level of the map in (a). The thick diagonal line in (a) shows the position of the mean SPCZ precipitation axis. Black areas signify areas where data is not available.

(a)

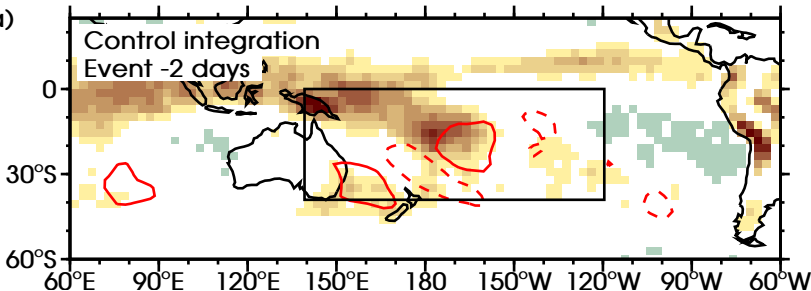

(c)

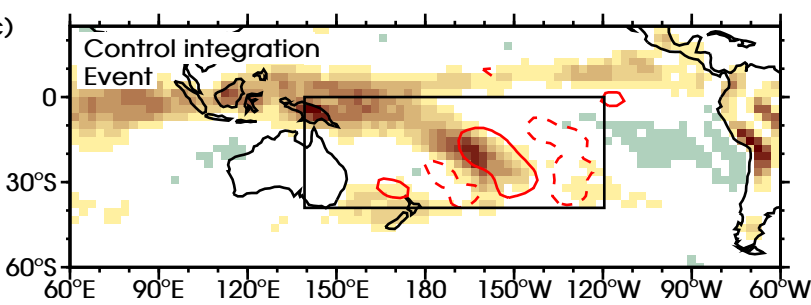

(b)

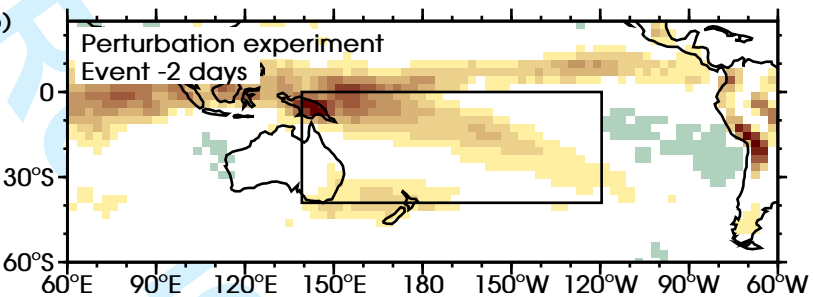

(d)

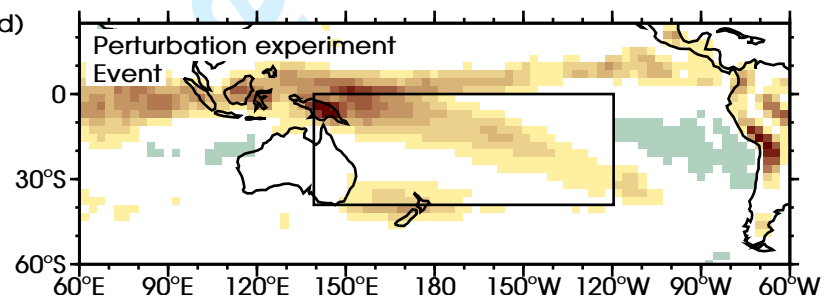

(e)

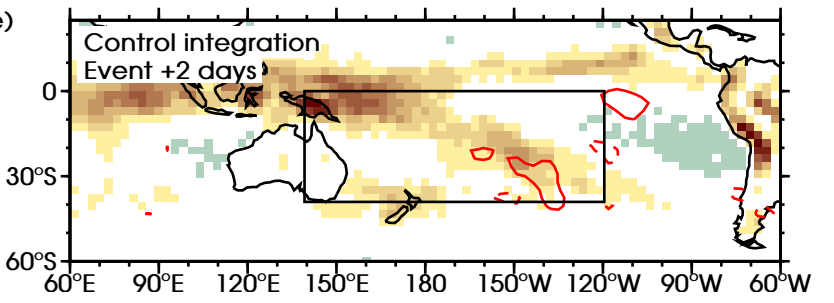

(f)

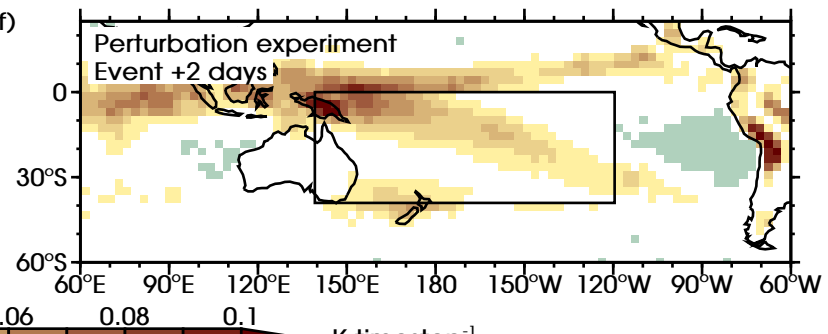

Figure 6. Composite mean temperature tendency due do deep convection at $\sigma=0.54$ in shaded colours (K timestep ${ }^{-1}$ ). (a,c,e) show the instantaneous, self-consistent model computed tendency in the control integration. In the perturbation experiment this is replaced by the climatological tendency within the experiment region (black

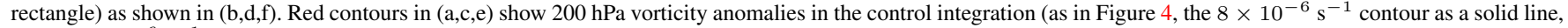
the $-8 \times 10^{-6} \mathrm{~s}^{-1}$ contour as a dashed line). 

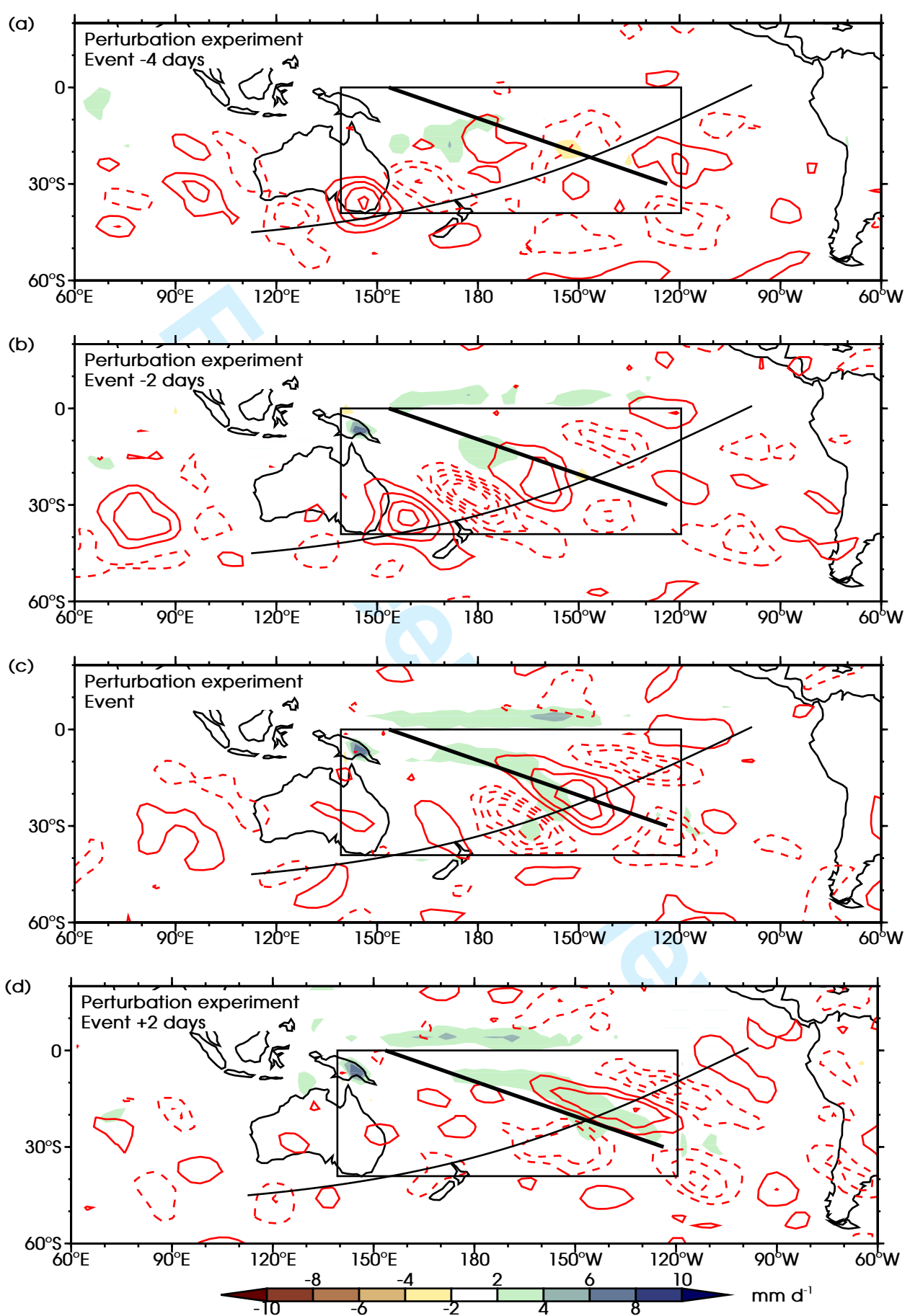

Figure 7. As Figure 4, but for the perturbation experiment. Note (a) is the same as Figure 4a, the starting point of the pertubation experiment. The rectangle indicates the region for the perturbation experiment. 

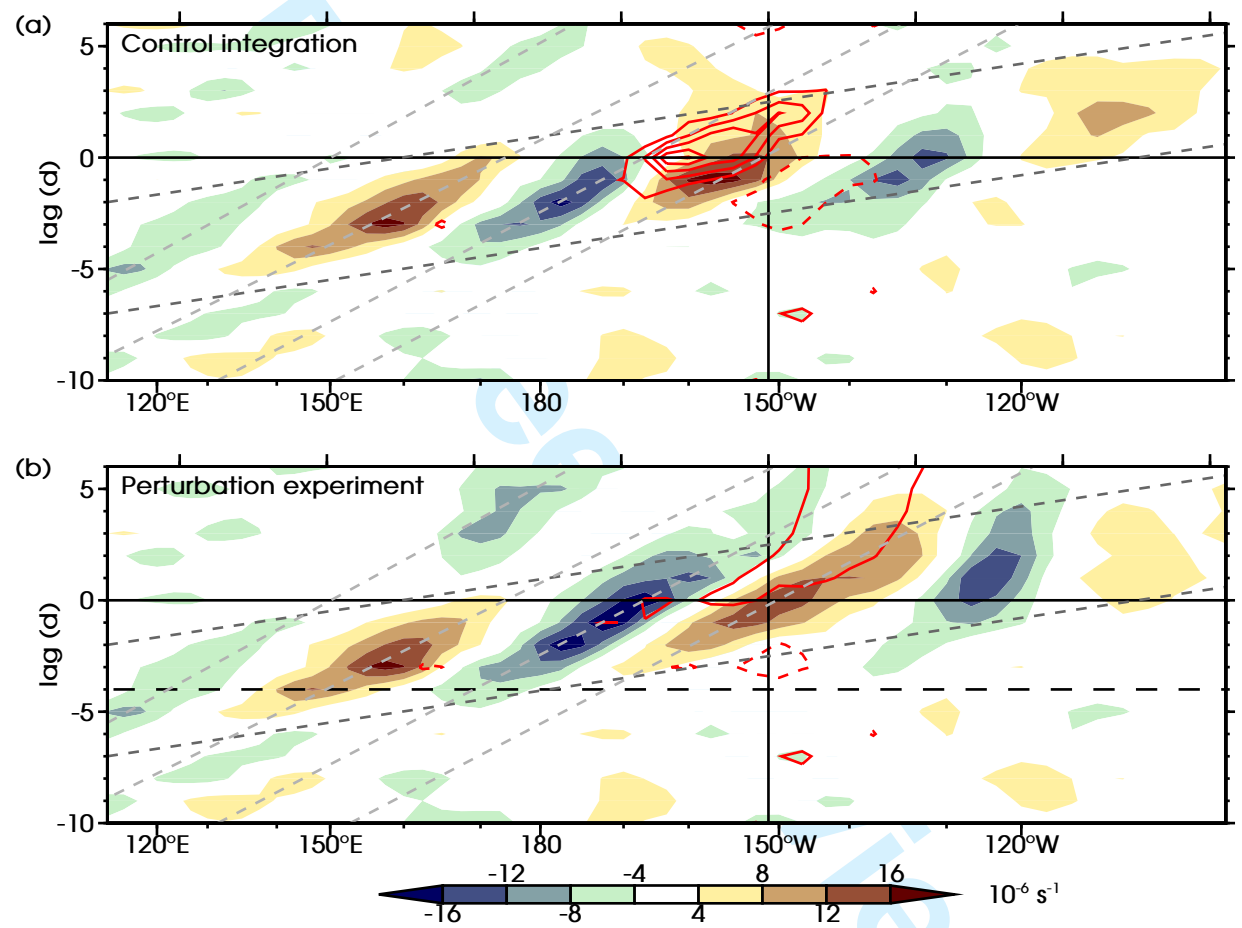

Figure 8. Hovmöller diagram of lagged composite anomalies along the curved propagation path in the (a) control integration (Figure 4) and (b) perturbation experiment (Figure 7). The $200 \mathrm{hPa}$ vorticity is shown in shaded colours $\left(10^{-6} \mathrm{~s}^{-1}\right)$ and precipitation in red contours $\left(2 \mathrm{~mm} \mathrm{~d}^{-1}\right.$ contour interval, zero contour omitted, negative contours dashed). The vertical solid line denotes the position of the mean SPCZ axis, the horizontal dashed line in (b) is the beginning of the restart integrations at event -4 days. Light grey dotted lines show the approximate phase speed, dark grey dotted lines the approximate group speed. Horizontal axes are irregular longitude (bottom) or regular distance (top, $2000 \mathrm{~km}$ intervals) along the path. 
(a) 3

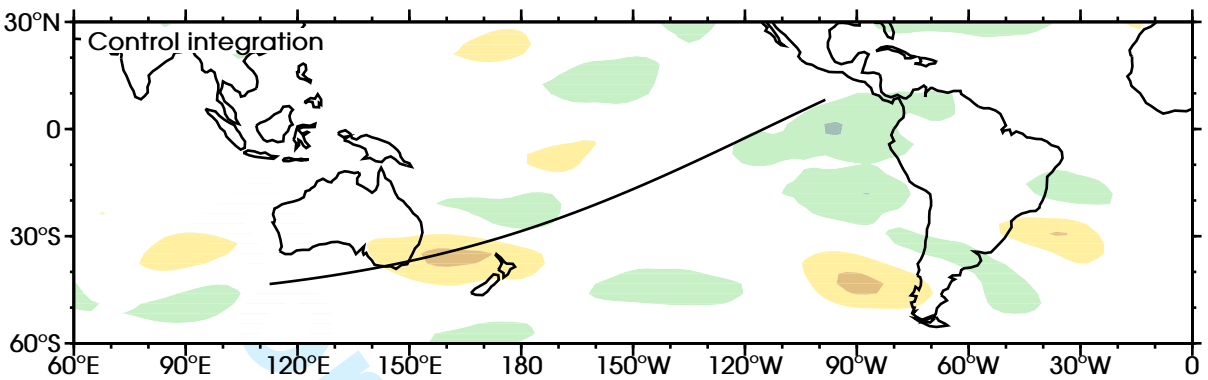

(b) 30

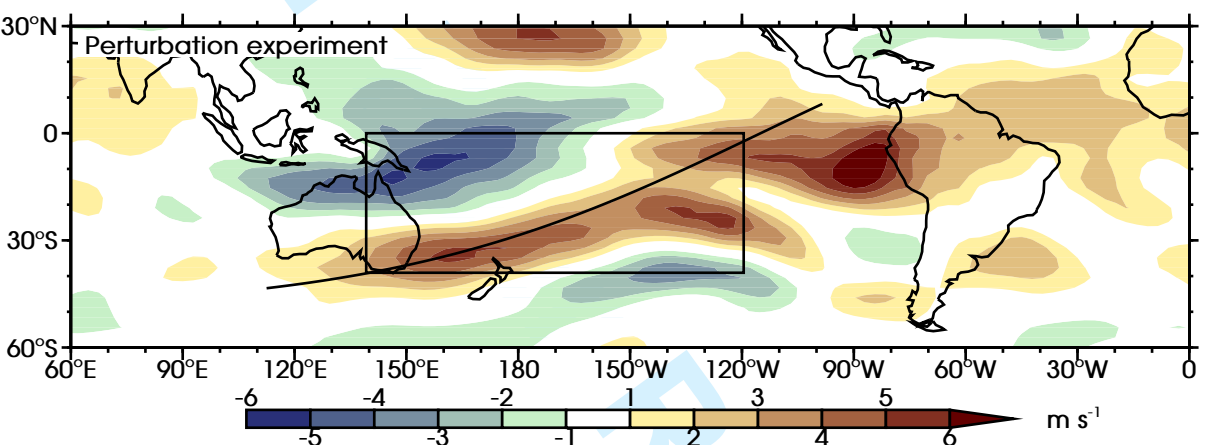

(c) $30^{\circ} \mathrm{N}$

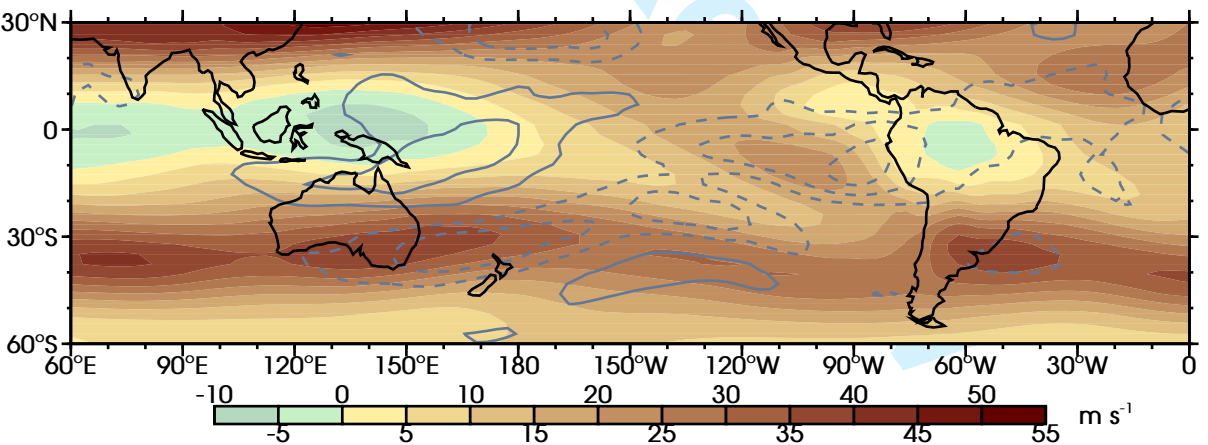

Figure 9. Mean $200 \mathrm{hPa}$ zonal wind anomaly $\left(\mathrm{m} \mathrm{s}^{-1}\right.$ ) over composite days event +6 days to event +10 days for the (a) control integration, and (b) the perturbation experiment. The curved line an approximate wave propagation path, the rectangle in (b) indicates the region for the perturbation experiment. (c) Time mean $200 \mathrm{hPa}$ zonal wind (November to April) in the control integration in shaded colours ( $\mathrm{m} \mathrm{s}^{-1}$ ) and SPCZ convective event wind anomaly (b) overlaid in grey contours, note the sign has been changed from (b) $\left(2 \mathrm{~m} \mathrm{~s}^{-1}\right.$ contour interval, zero contour omitted, negative contours dashed). 